\title{
Anacrusa, comienzo y silencio. Blanchot y la voz (no humana) venida de otra parte
}

NOELIA BILLI Universidad de Buenos Aires - CONICET, Argentina / noelia.billi@conicet.gov.ar

\section{Resumen}

En los textos que dedica a Louis-René des Forêts, Maurice Blanchot profundiza sus análisis de la curiosa coexistencia de la voz, la muerte y el silencio que se da en la figura del infante. Allí ambos escritores se encuentran ante una voz que, viniendo de lo no humano (del espacio de ultratumba), es inasignable y resiste el pasaje a la significación que caracteriza al Hombre. En el recorrido que proponemos se hace manifiesta una voz que no se opone ni excluye al silencio, y un silencio que no deriva del callarse de la palabra. De tal manera, la diferencia inaudible entre naître (nacer) y n'être (no ser) adquiere el furor calmo de esos enigmáticos poemas de des Forêts, el poeta que sumido en el mutismo halló que para no escribir tendría que escribir sin fin hasta el fin (o a partir de él).

Palabras clave: Blanchot des Forêts / infante / silencio

\begin{abstract}
Anacrusis, beggining and silence. Blanchot and the (non human) voice from elsewhere

Abstract

In the texts dedicated to Louis-René des Forêts, Maurice Blanchot deepens his analysis of the curious coexistence of voice, death and silence that occurs in the figure of the infant. Both writers find themselves facing a voice that, coming from the non-human (from the space beyond the grave), is unassignable and resists the passage to meaning that characterizes Man. In the itinerary we propose, a voice that does not oppose or exclude silence appears, as well as a silence that does not derive from the silence of speech. In such a way, the inaudible difference between naittre (being born) and n'être (not being) acquires the calm fury of those enigmatic poems of des Forêts, the poet who, immersed in mutism, found that in order not to write he would have to write endlessly until the end (or from out of it).
\end{abstract}

Key words: Blanchot des Forêts / infant / silence

Recibido: 14/5/2018. Aceptado: 22/6/2018

Para citar este artículo: Billi, Noelia (2018). Anacrusa, comienzo y silencio. Blanchot y la voz (no humana) venida de otra parte. El taco en la brea, 8 (junio-noviembre), 12-20 Santa Fe, Argentina: UNL. DOI: 10.14409/tb.v1i8.7740 


\section{La infancia: síntoma y acontecimiento}

Si hay temas que impregnan y obsesionan la escritura blanchotiana son los de la palabra y la muerte. No obstante, estas no mantienen a través del tiempo las mismas relaciones: si bien parecen inescindibles, a veces se oponen - la palabra es, como quería Hegel, lo que mata a la cosa-y, otras veces, son dos modos de nombrar el mismo desplazamiento respecto del "yo», de modo que tanto la palabra como la muerte implican una relación de extrañeza respecto de lo claro y distinto, y fuerzan la exposición intolerable a lo otro, que es también la pasividad que conmociona toda asignación de sujeto.

Proponemos aquí llevar adelante una lectura «sintomática» de la noción de infancia presente en un conjunto de textos que Blanchot publicó acerca del escritor francés Louis-René des Forêts (1918-2000), y que llevan el sugerente nombre de Anacrusa (cf. Blanchot 2002:7-44). Retomando el sentido derridiano del síntoma (Derrida:104-106), mentaremos aquello que, a diferencia del signo, no depende de la convencionalidad comunicativa, sino que posee el valor acontecimental de lo que a cada uno le cae verticalmente, por fuera de la intencionalidad, el cálculo y la previsión. Lejos de una lectura totalizante o sistemática, intentaremos señalar algunas de las preocupaciones recurrentes de la obra de Blanchot y la deriva particular que adquieren en este conjunto que forma parte de su producción tardía. Desde esta perspectiva, lo que relevaremos como síntomas serán los pequeños acontecimientos que ambos escritores parecen compartir y que, en lugar de señalar una identidad entre ambos, tan sólo funcionan como indicios de una común obsesión que ninguno resuelve.'

Ambos escritores abordan la palabra remitiéndose a su nacimiento en la constelación que aúna silencio e infancia. La original lectura de esta última — no ya como «falta de voz» que sólo tendría entidad a partir de una comparación con la adultez parlante, sino a modo de potencia que no se extingue en el acto de habla — tiene por resultado una renovación de las nociones de palabra y de muerte, alejándolas del «mero» nihilismo y acercándolas al roce con lo que hay antes y después de la emergencia y el cataclismo humanos.

\section{No ser (parlante)}

No ser es aquello que parece caracterizar al hombre, al menos desde la modernidad. De hecho, para el pensamiento del siglo 20 francés —inspirado por las lecturas antropológicas de Hegel realizadas por Kojève y de Heidegger realizadas por Sartre — este no ser toca la esencia de lo humano toda vez que este es definido por la muerte (no ser radical), operando así una duplicidad conceptual a partir del desdoblamiento semántico del fin: la muerte como final del hombre es a la vez la finalidad última del hombre, versión moderna del aristotélico motor inmóvil que constituiría el alfa y el omega de toda la metafísica occidental. «No ser parlante» será la ambigua definición de lo humano sobre la cual avanzará este siglo: el hombre es el no-ser que habla (es el animal que tiene el lenguaje como diferencia específica), pero a la vez es el ser que no-es-parlante por naturaleza (de donde emerge la idea de una tecnicidad originaria de lo humano que constituiría la quintaesencia de su separación respecto de lo animal). En términos lingüísticos, este no ser será traducido a un silencio que primero antecede a toda palabra posible — es el silencio del infante que muere para dar lugar al adulto parlante- y luego es el solo derivado de la privación de la palabra —el silencio como falta o negativo de la palabra - A partir de esta descripción, puede empezar a sospecharse un vínculo funcional entre el silencio y la muerte, pues ambos parecen entablar la misma clase 
de relaciones: la muerte es concebida como lo negativo de la vida, lo que la rodea amenazante, precediéndola y tomándolo todo cuando ella se debilita y finalmente termina. En la dimensión ontológica, la muerte en tanto negativo de la vida será reconvertida en una posibilidad humana, según un proceso de idealización que Blanchot localiza paradigmáticamente en el pensamiento hegeliano: será «el acontecimiento indescriptible que está perdido, tergiversado por nosotros, gracias a un sorprendente subterfugio, en medio de vivir y en poder de pensar» (Blanchot 1969:49). En tanto necesaria mediación de la vida y el pensamiento, la muerte será un principio antropogénico: aquel lugar último en que el hombre debe conquistarse, lo que debe ponerse al servicio de los hombres para que estos sean. En este contexto, silencio y muerte son pensados de acuerdo a la misma lógica: el silencio es aquello que debe combatirse hasta que desaparezca y el habla sea posible. El infans debe morir para que el hombre hable. ${ }^{2}$ No llamará la atención a nadie que muerte y silencio guarden un vínculo tan estrecho que parece indestructible, y ello se debe en parte a un funcionamiento idéntico que homologa ambas nociones en la dimensión de las operaciones conceptuales que habilitan.

\section{Infancia y silencio}

Las intervenciones blanchotianas en torno a la muerte recusan la perspectiva antes esquematizada: de acuerdo al pensador francés, la muerte no es un «término» con el cual se pueda mantener relación alguna, es decir, la muerte no es ni puede ser ubicada como la fuerza que aumentaría el poder del hombre. Blanchot denuncia apasionadamente los caminos literarios, filosóficos y políticos que reconducen la muerte al lugar de lo verdadero, develando que la manera más insidiosa en que ello se ha llevado a cabo es idealizando la muerte, transformándola en lo absoluto. En efecto, concebir la muerte como una unidad pura y absoluta - sea positiva o negativa - supone una tentativa de dominarla, pues es en el ámbito de la absolutez donde ella adquiriría un poder que operaría como principio lógico (como pura negatividad) y ontológico (como pura finitud inmaterial) (Blanchot 1969:46-69). Blanchot insistirá en que morir ${ }^{3}$ es lo imposible y si ello algo asegura es que lo que hay implica un nomadismo que nos arroja incansablemente a lo impersonal. Así pues, la muerte es aquello que inquieta al hombre en la medida en que éste no puede apropiársela transformándola en un posible, en una vía de aumento de su poder: no es lo que nos abisma en la angustia de un no ser presente o futuro, sino el puro devenir que impide la quietud y la certeza, incluso la certeza en la propia finitud (de donde la importancia de la cuestión espectral en la obra blanchotiana: ¿estamos seguros de morir? ¿Acaso no somos asediados por fantasmas que una y otra vez sugieren que morir es eso imposible que no termina de suceder nunca?).

En consonancia con esta perspectiva original de la muerte, Blanchot tratará la cuestión de la infancia y el silencio de un modo distinto al habitual. Si la infancia habría de representar el silencio que se opone excluyentemente a la voz, a partir de los textos blanchotianos dedicados a des Forêts puede decirse que es preciso indagar en una voz infantil que no sea reductible al silencio, o dicho de otro modo: en un silencio que no sea el negativo de la voz. La idea de Blanchot cobra fuerza al comprender que este es el modo en que la tradición hace persistir en torno a la "negatividad» del silencio la misma lógica que reseñábamos para la noción de muerte. Poco importa si la infancia - y el silencio que le es asociado - son valorados positiva (en cuanto que el silencio garantizaría un acceso inmediato a las cosas, y la infancia un contacto más puro con el mundo) o negativamente (en contraste con el adulto parlante que se empodera cada vez que mata las cosas 
nombrándolas): en ambos casos la infancia es construida en oposición exclusiva y excluyente respecto de la voz significativa. ¿Cómo pensar una voz por fuera de este esquema?

\section{La voz del infans}

¿Qué es la voz? Para cierta mirada que caracteriza la filosofía de los últimos siglos, la voz se ha convertido en un sinónimo de «naturaleza». Estar privado de voz será equivalente a estar privado de naturaleza, y obligará a darse como tarea su creación o producción (ahora sí, artificial o naturalmente técnica). ${ }^{4}$ La construcción conceptual de esta posición excéntrica respecto del medio en que habita ha permitido un pensamiento «negativo» del animal humano: en apariencia carente de positividad que pudiera definirlo, extraerá una ética, una política y una metafísica de su poder no ser natural, de poder no ser lo que «es». Ni dios, ni animal ni máquina, el hombre reunirá en torno a sí y manipulará en su favor aquello que también se define en el ámbito de lo negativo, a saber, el lenguaje (entendido saussureanamente, como sistema de diferencias) y, sobre todo, la muerte. En esta línea, la voz parece señalar un enclave aporético, por cuanto implica la presencia (positiva y empírica) de una individualidad «viva» que se emplaza en el centro de la negatividad: una presencia que de inmediato desaparece en cuanto deviene el soporte material transparente de una pulsión de comunicación. Así, la voz atraviesa los umbrales que separan lo vivo de lo muerto, lo presente de lo ausente, lo positivo de lo negativo, incapaz de permanecer en ninguno de estos ámbitos; a la vez, su juego de aparición-desaparición es lo que parece caracterizar lo humano en tanto es la inquietud que se arranca a sí misma de todo ámbito de pertenencia pero utilizándose a sí misma como plataforma de lanzamiento más allá de sí. Conceptualmente, la voz queda así presa de la hipótesis humanizante-idealizante según la cual siempre prevalece la voluntad de significación que permite que cualquier sonido emitido por el hombre sea interpretado como voz significativa.

$\mathrm{Si}$, como sabemos, Blanchot liga la palabra a la muerte, atribuyéndole así el ámbito de lo impersonal como sede de su dinámica, ¿cómo es posible comprender la voz en dicho emplazamiento? Su tratamiento de la infancia constituye una entrada privilegiada a esta constelación, en ese punto mudo por exceso (pero no por privación) que es la anacrusa, ese modo de la infancia que se reparte entre Blanchot y des Forêts. ${ }^{5}$

\section{Una voz venida de otra parte}

El texto que, en exergo, da comienzo a Anacrusa es un extracto de Ostinato, por L. R. des Forêts: ${ }^{6}$ "Que nunca la voz del niño en él se calle, que ella caiga como un don del cielo ofreciendo a las palabras resecas el estallido de su risa, la sal de sus lágrimas, su todopoderoso salvajismo» (des Forêts en Blanchot 2002:11).

Si el infante - en su mismo nombre - se caracteriza por no tener voz, que en el comienzo el niño la tenga es una señal de la búsqueda compartida por ambos autores, búsqueda que es su común sintomatología. La voz del niño será el acontecimiento silencioso que caerá a cada uno en las propias-impropias («resecas») palabras. Es esta la voz que no habla sino riendo y llorando, en un estado silvestre que parece hacer señas hacia un tipo particular de poder que es el de lo informe («su todopoderoso salvajismo»). El niño se caracterizaría por su pertenencia a lo todavía-no-humano; sin embargo, él y su voz silente pero afectiva y sensible —en oposición a la voz significante («reseca») - serían lo que no deja de acontecerle al hombre: le caen verticalmente, escapando a su poder de previsión y de cálculo. ¿Qué sucede entre la voz silenciosa del niño y la del adulto (el 
humano)? ¿Cuál sería la voz venida de otra parte que Blanchot nombra en su texto? En ella, el silencio no se encuentra enlazado oposicionalmente a la palabra, sino que indica quizás el locus de una palabra sin significación, un silencio de la significación que atraviesa la palabra significativa. Pero, ¿no estaríamos instalándonos nuevamente en el cómodo paradigma de una palabra caracterizada por aquello que no es — por el silencio, en este caso-? Por el contrario, lo que se indica es que no hay una posición excéntrica de la palabra humana (aparentemente caracterizada por la privación de voz «natural»), sino que la falta de voz humana es el resultado de una operación mediante la cual la voz venida de otra parte es reducida al silencio en la figura del infans.

Así pues, se dirá del infans que es silente porque carece de voz significativa, lo cual implica una doble consecuencia: por una parte, que la infancia sería un estadio pre-humano, cuyo silencio constituye una especie de «estar en la naturaleza» que se eliminará en el pasaje a la adultez y su voz significativa; por otra parte, que el concepto de voz se reduce a la voluntad de significar, condición de posibilidad de todo horizonte hermenéutico posible (por más difuso o regulador que quiera ser). Aceptado esto, asistiríamos a una escena en la cual o bien se es un animal (pre-humano) sin voz de ningún tipo y en contacto (silencioso) con la naturaleza, o bien se es un hombre que se ha arrancado a sí mismo de la naturaleza a través de la producción de una voz (artificial). En este escenario, ¿cuál podría ser la voz venida de otra parte? ¿Y de dónde viene?

\title{
La voz no humana
}

Blanchot hace resonar la intuición de des Forêts: la voz desconocida adviene como un donacontecimiento que cae desde el cielo, de forma imprevisible y alterando las palabras del hombre. También recoge otra indicación del poeta, que la nombra como voz de ultratumba:

\author{
Samuel, Samuel, ¿es esa tu voz la que oigo \\ Venir como desde las profundidades de una tumba \\ Reforzar la mía enfrentada a las frases \\ O hacer eco a su gran indigencia? ${ }^{7}$
}

¿Qué es lo que hace síntoma cuando la voz viene de lo no humano — de la ultratumba, del cielo-? Asistimos al esfuerzo por pensar una voz que no depende de la voluntad de significación asociada al hombre, una voz que habla desde y con el silencio. Lejos de ser un mero oxímoron, es preciso demorarse en lo supone una voz que aflora del silencio sin anularlo, que es el silencio que habla una voz no humana, es decir: una voz que no se opone ni excluye al silencio, y un silencio que no deriva del callarse de la palabra, sino que proviniendo de las cosas resulta inapropiable por el hombre - y que debido a ello éste quiere todavía imponerse significándolo como silencio absoluto- En el mismo horizonte se recorta otra de las figuras destacadas por Blanchot, la Sibila, cuya «sabiduría falta de razón [déraisonnable] (...) se hace escuchar durante mil años, porque nunca es escuchada ahora» (2002:57) ¿Hablan, pues, las cosas, los monstruos, los dioses? ¿Hay una voz de lo muerto?

\section{Ostinato}

En «El blanco El negro» el derrotero del comentador (Blanchot) y del comentado (des Forêts) se confunden en un punto abismal que a ambos deja al borde del silencio, cuando el primero mienta 
«el desastre absoluto [que ha sobrevenido a des Forêts]. Tras lo cual se ha visto privado de sus dotes de escritura», y se llama a silencio al bosquejar su propia incomodidad respecto de la «insuficiencia del comentario» (2002:15 y 17). El objeto que está en el centro es el antes mencionado Ostinato, cuya escritura fragmentaria estuvo en suspenso durante años y finalmente retornó como los restos de un naufragio «donde quien escribe fue algo así como tragado» (15). Blanchot se apoya en este nombre - Ostinato- - que conjuga un motivo musical y uno existencial, para aludir a la tarea del escritor: para quien escribe, ello no es una actividad dominable a través de la voluntad, es una «condena, incluso una maldición» (16). Lejos de la palabra que expresa a la subjetividad yoica e individual que se concibe como una interioridad cerrada sobre sí, la voz del escritor impugna la primera persona y constituye la perdición de quien no puede sino ser el testigo de lo que le acaece más allá de su voluntad. Del mismo modo en que, en términos musicales, se llama ostinato a la resonancia indefinida de una única nota que no acaba de desarrollarse (y que por eso nunca tiene un final), la voz que asalta al escritor no tiene algo para decir sino que es la mera comunicabilidad de eso impersonal que es la esfera en la cual el sujeto emerge y de la cual cree, ilusoriamente, poder evadirse.

De acuerdo a Blanchot, des Forêts revela que el único modo de guardar silencio es escribir. En una refutación práctica de la máxima wittgensteiniana según la cual «de aquello que no se puede hablar, hay que callar», él no será capaz de hacerlo sino entregándose desenfrenadamente al habla, a la escritura: «Sólo hay blancos si hay negro, sólo silencio si el habla y el ruido se producen para cesar» (2002:24). He allí la precariedad expuesta del fragmento que espeja la fragmentariedad de la existencia: el blanco que separa cada pequeño acontecimiento de escritura de otro es el único inestable alivio que el hombre es capaz de obtener de la voz que lo asedia más allá de sí, que lo enferma y obliga a llenar hojas y hojas sumido en un tormento interminable (sobre la prensión persecutoria, cf. Blanchot 1955:15-16). ¿En cuál de estas instancias el hombre está más acallado? ¿Cuándo es tomado por el habla que lo excede y escribe sin saber qué expresa ni con qué objeto? ¿O cuándo encuentra reparo en el silencioso umbral que separa un fragmento del otro? ${ }^{8}$ Lo que se insinúa es la imposible necesidad de alcanzar la quietud, aunque ella no fuera más que «la fractura definitiva» que precipitara la voz para siempre en el vacío (2002:26). El único silencio que le es accesible voluntariamente a este hombre es el que proviene de la palabra, impedido como está para remontarse a un estadio prelinguístico. Por otro lado, lo obsede el silencio que constituye el fondo inestable de toda escritura: para él, la palabra equivale al silencio toda vez que aquella nunca pertenece a la primera persona sino que la toma, la despoja y la arroja a lo impersonal donde no es posible decir «yo».

\section{Anacrusa}

\footnotetext{
¿Dónde está el comienzo? ¿Hay alguien o algo que comience?
}

Blanchot 2002:29

La inaudible diferencia entre naître y n'être (no ser y nacer, homófonos en francés) parece signar la noción de infancia que presenta Blanchot. Recogiendo la inquietud de des Forêts, que indica que el no ser que antecede a la existencia (de donde se nace) genera más sufrimiento y temor que aquel donde la existencia acaba (el de la muerte), el pensador mostrará que el no ser no se halla sólo en los dos extremos de la vida, sino que la atraviesa y perfora de lado a lado, haciendo de la existencia 
(de lo que hay) una cadena de pequeños dijes de ser cuyo hilo invisible es el no ser. Así, el verso de des Forêts, "Dite que no terminamos de nacer»," señalaría un no ser asociado al nacimiento: no tanto un no ser de donde se nace sino un no ser que nace, la introducción del no ser en la existencia, el comienzo cada vez reiterado formando un intersticio en lo que hay. A diferencia del comienzo pensado como acción — a partir de una lógica intencional según la cual el sujeto instrumenta los medios en pos de un objetivo-, este comenzar hace señas hacia el acontecimiento imprevisible (el «peut-être», escribe Blanchot), que hace de lo existente el «terrible vaivén del HAY (el ser cree recuperar el no ser, pero el nacimiento en su no ser se obstina — Ostinato - sin haber entregado todavía su secreto)» (2002:42. El subrayado es del original).

En lugar de pensar la existencia humana como aquella que cae en la nada y que se orienta a su no ser (como ser para la muerte), se trata para Blanchot de la caída de la nada en la existencia, revirtiendo así el desequilibrio en el doble no ser (no ser como nacimiento y no ser como muerte) del que toda la modernidad se nutre a la vez que ayuda a construir. La exigencia a la que nos somete esta reversión es casi intolerable: «¿por qué nacer? ¿Por qué no terminamos de nacer? ¿Por qué nos queda, más allá del propio fin (y el fin ¿es el no ser absoluto?), algo así como un inicio?» (33-34).

La cuestión de la radical extrañeza de la existencia es introducida subrepticiamente. Debe adoptarse el punto de vista del otro (autrui): el nacimiento no alude a la propia experiencia de nacer sino al acontecimiento que cae en la existencia poblada de otros. El niño «no puede por tanto parar de nacer, SENTENCIA de nacimiento»..$^{10}$ Detenido en y arrojado al umbral de lo que existe pero no es su propia existencia, el infante cae al mundo y añade una voz que escapa al lenguaje puro de la significación, a ese lenguaje que sólo quiere existir como el medio transparente que un yo utilizaría para expresarse. Sin yo, con el consentimiento que le brinda «el dolor extremo», la infancia se entrelaza con la literatura pues ambas se cifran en el «NON SERVIAM» que hace de sus voces no el instrumento de un sujeto sino fuerzas que reúnen el agotamiento y lo inagotable, el n'être y el naître, «la DESAPARICIÓN que no se extenúa» (38). Nacimiento e infancia nos atraen hacia el espacio difuso que es el reino de lo impersonal, la impugnación que no se reduce a la negatividad, el ámbito de lo que se congrega y disgrega formando una existencia en que «el no ser no se abole en el ser» (41) ni el silencio es aniquilado por la voz. Lo impersonal revelado en la infancia se configura como aquello que no puede ser experimentado en primera persona, como la experiencia que se da en y como contratiempo, que se insinúa a través de las palabras pero no mediante ellas, sino bajo las formas de su timbre, su música, su ritmo. Es el síntoma de des Forêts, indigente de la palabra forzado a habitar entre los restos insignificantes que se constelan en torno a la infancia («los gritos de los pájaros», el «alborozo de las criaturas del cielo», los «cantos que escapan de la necesidad infernal del lenguaje» - 34-), restos que no pueden ser inscritos en una totalidad de sentido y tampoco aniquilarse. Es el síntoma de Blanchot, que elucida el contratiempo del poeta acercándolo a la versión moderna de la anacrusa, instancia primera en la que

no se escucha nada o un tono tan débil que parece que falta y por eso dura sin duración o más bien no dura, de modo que tras él o a partir de él la nota finalmente tocada se eleva hasta un estallido a veces prodigioso, estallido o impulso tan fuerte que sólo puede recaer — caída — en un nuevo silencio. (42. El subrayado es mío)

La infancia como anacrusa habrá de concebirse a modo de umbral en que se sostiene la desaparición: no el silencio absoluto que preludia la voz o la música (la anacrusa griega que Blanchot 
se apura a desechar) sino más bien la perpetua inauguración (nacimiento, caída) de una voz que reconcilia canto y habla. Se trata de un silencio que se entona, y que por eso no se identifica con lo puramente negativo sino que, por el contrario, hace vacilar la diferenciación entre lo que aparece y desaparece, lo que habla y calla. Sin que ello implique la confusión de lo indiferenciado: en la anacrusa, lo que altera la idea de un silencio puro previo a la voz (de una infancia absoluta que desaparece con el habla) es el desplazamiento temporal que impide que el antes y el después se fijen. Ello habilita una noción de lo que hay que es excesiva, en la que conviven no reconciliados ser y no ser, en la que los silencios, los gritos, las preguntas, los alborozos son concebidos como las esquirlas de no ser que sin cesar caen y atraviesan la existencia.

Por eso quizás sea aquí pertinente tomar distancia de las lecturas de Blanchot que lo señalan como el amante del abismo, como alzando un pensamiento en el cual prevalece la pura negatividad, la pura nada: una nada que sería así muy parecida a esa muerte cuya función antropogenética el escritor ha impugnado. Antes bien, en Blanchot se constata la lucidez del ciego que se echa a andar sin rumbo entre los fragmentos, obsedido por hallar la "fractura definitiva» que lo salvaría al hundirlo en el vacío, pero que sabe que tropezará sin remedio con las piedras inanes que se obstinan en la existencia, que sabe que su llamado será respondido por un diluvio desmesurado de piedra que estremecerá la tierra y el cielo (Blanchot 1955:204). Tal vez, junto a des Forêts, él estaría dispuesto a afirmar que "no es ni él ni yo, es el mundo lo que habla. Es su terrible belleza» (des Forêts:66).

\section{Notas}

1 Los estudios sobre Blanchot y des Forêts abrevan en su mayoría en la lectura que intenta el ensayista de la novela Le bavard. Cf. Kaufman, Rabaté.

2 Sobre el lugar preciso en que se anudan la muerte del infans y la emergencia del hombre, cf. Billi.

3 No nos detendremos aquí en la distancia entre la muerte y el morir elaborada por Blanchot a través de su obra. No obstante, digamos que el morir se liga a lo impersonal y al tiempo retornante de la existencia que Blanchot reivindicará. La distinción entre ambas nociones se halla completamente desplegada en La escritura del desastre, donde Blanchot anota: «Habría en la muerte algo más fuerte que la muerte: es el morir mismo (...). En la muerte, es posible refugiarse ilusoriamente, la tumba marca la detención de la caída, lo mortuorio es la salida del callejón sin salida. Morir es lo huidizo que arrastra indefinida, imposible e intensivamente en la huida» (1980:81).

4 Cfr., por ejemplo, Heidegger:54-60. Allí se afirma que mientras cada animal tiene su voz particular, el animal humano es aquel a quien esta voz falta. Heidegger añade a la falta de voz un valor ético que será la especificidad de lo humano: sobre el fondo de este «silencio», la voz de la conciencia acontece. Cfr. Dolar.

5 Puede consultarse Lafond para una lectura que diverge parcialmente con la aquí presentada, sobre todo en cuanto que la autora profundiza en la relación que, en este texto, Blanchot mantiene con el pensamiento de Lévinas en torno al Decir (Dire). Si existe divergencia no es tanto por un conflicto de interpretaciones sino más bien porque al atar la lectura blanchotiana a la filosofía levinasiana, aquella necesariamente ve reforzados sus aspectos éticos y, por tanto, humanos. De acuerdo a la interpretación aquí ofrecida, Blanchot encuentra en des Forêts la posibilidad de expandir las resonancias de lo inhumano de la voz.

6 Ostinato es considerado una biografía a la vez que la publicación «final» de un work in progress, «final» que no impide que permanezca inconcluso, que revela que la inconclusión era su única y obstinada forma posible.

7 «Samuel, Samuel, est-ce bien ta voix que j'entends/ Venir comme des profondeurs d'un tombeau/ Renforcer la mienne aux prises avec les phrases/Ou faire écho à sa grande indigence?» (L.-R. des Forêts, Les poèmes de Samuel Woods, citado en Blanchot 2002:19). 
8 Que des Forêts ha experimentado los alcances del silencio en la palabra, y sobre todo alrededor de la infancia, lo prueba la sostenida meditación de Blanchot en torno a su obra. En efecto, refiriéndose a su conocida novela Le bavard (traducida como El charlatán), dice: «Charlar es la vergüenza del lenguaje. Charlar no es hablar. La charla importuna destruye el silencio a la vez que impide la palabra. Cuando se charla, no se dice nada verdadero, aunque no se diga nada falso, pues no se habla verdaderamente» (1971:141).

9 «Dis-toi que nous n'en finissons pas de naître», Blanchot 2002:31.
10 «ne peut donc s'arrêter de naître, ARRÊT de naissance» (Blanchot 2002:33. Subrayado del original). Blanchot vuelve aquí a la ambigüedad que había explotado en L’Arrêt de mort (1948) entre la acepción más habitual de arrêt (detención, interrupción, parada) y su sentido en el sintagma arrêt de mort donde toma el sentido de "sentencia» en tanto orden que emana de una autoridad o poder superior contra la que no cabe luchar (cf. la entrada «arrêt» en Le Trésor de la Langue Française informatisé, disponible en: http://www.cnrtl.fr/definition/arret).

\section{Referencias bibliográficas}

Billi, N. (2012). «Matan a un niño». Muerte e infancia en Blanchot. Nombres, (26), 209-233.

Blanchot, M. (1948). L’Arrêt de mort. París: Gallimard.

- (1955). L'Espace littéraire. París: Gallimard.

(1969). L'Entretien infini. París: Gallimard.

(1971). L'Amitié. París: Gallimard.

(1980). L'Écriture du désastre. París: Gallimard.

(2002). Anacrouse: Sur les poèmes de Louis-René des Forêts. En Blanchot, M., Une voix venue d’ailleurs. París: Gallimard, 7-44 (recoge «Une voix venue d’ailleurs» (1989), «Le blanc Le noir» (1991) y «Anacrouse» (1992/1995).

Derrida, J. (2001). Une certaine possibilité impossible de dire l'événement. En G. Soussana y otros. Dire l'événement, est-ce possible? Séminaire de Montréal, pour Jacques Derrida. París: L'Harmattan, 81-112.

des Forêts, L.-R. (1997). Ostinato. París: Mercure de France.

Dolar, M. (2012). Une voix et rien d'autre. Caen: Nous.

Heidegger, M. (1977) [1929]. Sein und Zeit (trad. esp. Ser y tiempo). Gesamtausgabe I, band 2. Frankfurt am Main: Vittorio Klostermann.

Kaufman, E. (2003). The Delirium of Praise: Bataille, Blanchot, Deleuze, Foucault, Klossowski. Baltimore: Johns Hopkins University Press.

Lafond, N. (2010). Des Forêts, Blanchot et Lévinas: pour un «autrement dire».. En E. Hoppenot y A. Milon, editores. Maurice Blanchot et la philosophie: Suivi de trois articles de Maurice Blanchot. Nanterre: Presses universitaires de Paris Nanterre. http://books.openedition.org/pupo/1103 Rabaté, D. (1998). The Critical Turn: Blanchot Reads des Forêts. Yale French Studies, (93), 69-80. 